\title{
Detection and Analysis on a Vibration Workshop of Large-scale Coal Preparation Plant
}

\author{
Qiuxi LI \\ Civil engineering school \\ Anhui Jianzhu University \\ Hefei, China \\ e-mail: 823133343@qq.com \\ Dong CHEN \\ Civil engineering school \\ Anhui University \\ Hefei, China \\ e-mail: 630323651@qq.com
}

\author{
Dahua LI \\ Civil engineering school \\ Anhui Jianzhu University \\ Hefei, China \\ e-mail:1dh2006a@163.com
}

\author{
Chao SHEN \\ Civil engineering school \\ Anhui Jianzhu University \\ Hefei, China \\ e-mail: $984380505 @$ qq.com
}

\author{
Yelong ZHAN \\ Civil engineering school \\ Anhui Jianzhu University \\ Hefei, China \\ e-mail:1512844028@qq.com
}

\begin{abstract}
Based on detection of the Self-vibration and forced vibration the causes of resonant vibration on vibration are examined and analyzed, in order to improve the seismic capacity of coal preparation plant, the safety and normal use performance of coal preparation plant is guaranteed. The experimental result indicated that the reason make the device below the beam plate produce resonance is bending force of screening machine, the interference frequency of the screening machine is close to the first mode of the self-vibration while dynamic response increases of concrete along with the Stiffness of secondary beam and frame beam differ considerably.
\end{abstract}

Keyword-structural vibration; vibration frequency; frame structure

\section{INTRODUCTION}

With the development of coal screening, more screening equipments need to be installed on different floors to meet the demand of the production process, which made the workshop structure become more complex. Therefore, it was imperative to study the safety of the structure of large scale coal screening plant.

Overseas literature on the resonance of the workshop was carried out earlier. In 1988, the Swedish Building Research Committee released the floor vibration design guidelines, and made a preliminary summary of the formula for calculating the natural frequencies of the floor slab [1]. In 1990, Canada established some corresponding specifications for vibration design of wooden floor according to a series of research works in 70s [2] [3]. In 1997, Murray put vibration of structures under the microscope and put forward the limits criteria about acceleration of floor vibration [4]. Domestic researchers had carried out some work on the influence of resonance phenomenon of the building. Zhi Lunhai researches showed that the ideal vibration reduction effect could be obtained by separate the power equipment base or support from the main body of the plant structure [5]. Du Rui's research showed the maximum dynamic response of floor slab and there were significant differences between the amplitude of vertical and horizontal when the vibrating screen is installed in the adjacent axis [6]. Through monitoring the operation of the vibrating screen in the industrial factory, Xue Gang obtained the vibration acceleration and frequency, In the following, based on the analysis of the reason of the floor resonance, providing a scientific basis for the reinforcement of the structure [7].

\section{ENGINEERING SITUATION}

Coal screening plant was frame structure and be made up by reinforced concrete (C35), the plant have four layers, the top local containing jump layer. The height of the building is $31.1 \mathrm{~m}$, the longitudinal length of it is $92 \mathrm{~m}$ and the transverse length is $44 \mathrm{~m}$. The size of frame column is 700 $\mathrm{mm} * 700 \mathrm{~mm}$, the size of the main beam is $350 \mathrm{~mm} * 900$ $\mathrm{mm}$, the size of the secondary beam is $300 \mathrm{~mm} * 400 \mathrm{~mm}$ and the thickness of the cast in place concrete floors lab is $180 \mathrm{~mm}$.

Crushing unit and screening unit are all located in the fourth layer (Fig.1), Electromagnetic Separated Equipment installed in the three and second layer. During the operation of the units, workshop floor, doors and windows will produce larger amplitude of vibration and accompanied by 
external wall peel off, there are concrete cracks around the crack resistance and the bottom of the hopper. Additionally, due to the resonance of mechanical and structural, operators because of the frequent presence of symptoms of physical discomfort in practical production. Through the research on the structure and mechanical resonance of the large scale coal screening plant, a fast and efficient method for the dynamic detection of resonance is presented.

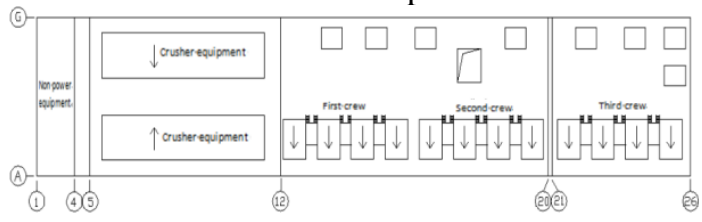

Figure 1. Equipment layout of the fourth floor

\section{DYNAMIC DETERMINATION SCHEME}

In order to detect the vibration frequency of the structure and the forced vibration frequency under different dynamic loads, the DZQ48/24/12 type high resolution seismic instrument was used as the testing instrument. The acceleration spectrum acquisition of the point position by using the pulse measurement function of the instrument and the acceleration spectrum is converted to frequency spectrum by digital filter (high and low band pass filter).

\section{A. Judgment of Vibration}

The second and third floors of coal preparation plant were electromagnetic separation equipment and speed of the smaller mixing equipment, the bending forces of the structure is small so that it cannot be a vibration source which induced by the obvious vibration of the structure. Observation revealed that floor vibration is more obvious at where the vertical transmission pipeline across the floor, so the preliminary judgment is that the vibration source which causing the vibration of the structure located on fourth layer where crushing unit and screening unit are installed. In addition, the propagation of vibration wave strengthened by crane beam with cross seismic joint in workshop and installation of steel structure working platform.

There were eight crushers installed on fourth layer, Each of the four every four machines as a unit and two units in the direction of rotation of the device (Fig.1 arrow); Screening machine a total of 12 units, every four units for a unit and three units of the device rotation direction is completely consistent (Fig.1 arrow). The dynamic detection is performed in accordance with the direction of the axis 1 to 26 to quickly and accurately determine the reason for the vibration of the plant. Detection point in the framework of the corner node, vertical and horizontal beams across the middle of the floor, the floor of the plane geometry center point, the acceleration time history curve of a point is obtained, which is converted to the frequency domain spectrum.

Experimental results showed that structure fundamental frequency is $14.8 \mathrm{~Hz}$ far higher than the $3.9 \mathrm{~Hz}$ (Fig.2); in the frequency spectrum of the 5 to 12 axis, more frequency of random interference (Fig.3), but the closer to the point of the screening unit, the less random interference frequency and the spot around it which Ideal frequency spectrum without interference frequency appeared (Fig.4). The maximum amplitude of sampled signal change from e+003 $\mathrm{mV}$ to e+005 $\mathrm{mV}$ during position measurement approaching Screening machine (Fig.3, Fig.4). It can be judged that the screening machine has great influence on the vibration of the structure. This analysis lays the foundation for the follow-up of the natural frequencies and the arrangement of the forced vibration detection schemes under different conditions.

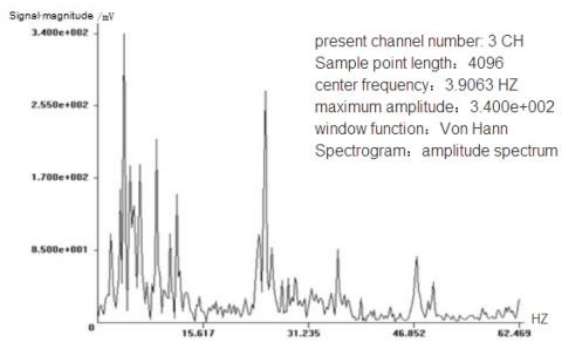

Figure 2. Frequency detection results of the structure

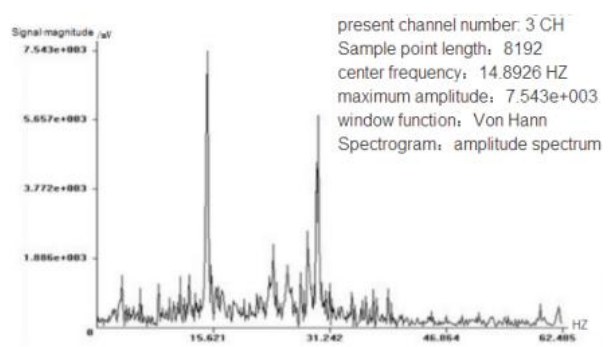

Figure 3. Frequency-domain picture of the points among axes 5 to 12

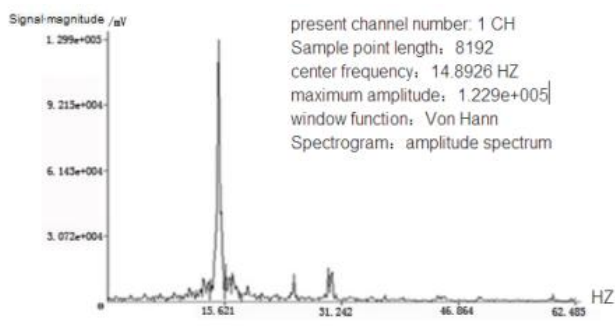

Figure 4. Proper frequency-domain picture

\section{B. Auto-oscillation Detection}

The vibration characteristics detecting of coal preparation plant perform after all units stop. Detection points and contents include: detection of the self vibration characteristics of $\mathrm{X}, \mathrm{Y}$ and $\mathrm{Z}$ directions of the frame beam column joints and the $\mathrm{Z}$ direction self vibration characteristics of the beam and the plate around the screening machine. Distribution of measured points as shown in Fig.5

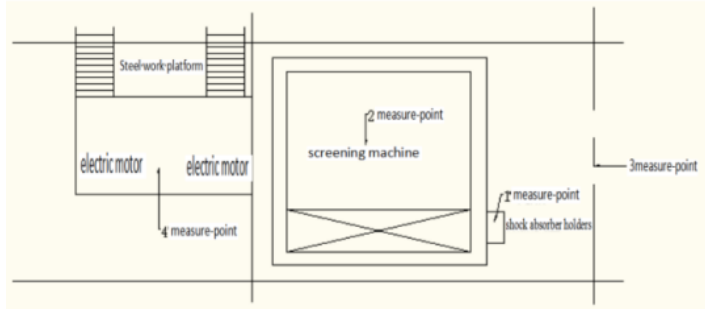

Figure 5. Schematic diagram of the points 
The 1 point is located on reinforced concrete foundation which under the absorber seat; namely located on secondary beam. The 2 point is located on the longitudinal frame beam which below the equipment; the 3 point is located on the transverse frame beam; the 4 point is located on the steel structure working platform. Convert acceleration time-history curves into frequency domain spectrum and filter processing Can get the fundamental frequency of the structure is $3.9 \mathrm{~Hz}$.

\section{Forced Vibration Detecting}

It is divided into three groups to measure the acceleration pulse according to the distribution of assembling unit. The first group only runs screening machine first assembling unit, the second group run screening machine first and second assembling unit, the third groups run all screening unit. Arrangement of points includes the point around equipment (Fig.5). The acceleration time history curves of beam, slab vertical ( $\mathrm{Z}$ direction) and beam column angular nodes are detected in the above mentioned cases. The results showed that in all three cases, the frequency of the point is $14.9 \mathrm{HZ}$, 14.7HZ, and $14.8 \mathrm{~Hz}$ in $\mathrm{Z}$ direction, namely, the forced vibration frequency of the structure is basically consistent. This shows forced vibration on Structure is irrelevant to number and placement of equipment.

\section{RESONANCE CAUSE ANALYSIS}

\section{A. Establish a Finite Element Model}

Combined with test results, in order to find out the reason of vibration, this thesis builds up an integrated finite element model by using the finite element software called MIDAS. The calculation model includes frame beam, secondary beam and floor slab (Fig.6), the calculation of natural vibration property of structure using Lanczos method, the first six mode frequencies and mode shapes were extracted (Table I ).

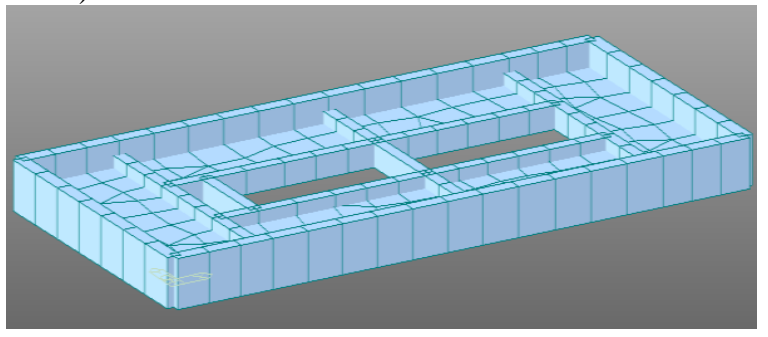

Figure 6. Calculation model of the structure

TABLE I. VIBRATION CHARACTERISTICS OF THE STRUCTURE

\begin{tabular}{clc}
\hline Mode & HZ & Mode Of Vibration \\
\hline The first mode & 14.1 & flat curved coupling \\
The Second mode & 16.4 & flat curved coupling \\
The third mode & 24.3 & flat curved coupling \\
The fourth mode & 25.2 & Bending and Torsion coupling \\
The fifth mode & 27.2 & Bending and Torsion coupling \\
The sixth mode & 33.7 & Bending and Torsion coupling \\
\hline
\end{tabular}

\section{B. Simulation Analysis}

The natural vibration frequency of the structure is $3.9 \mathrm{~Hz}$ and the deflection direction of the deflection of screening machine is vertical downwards and their frequency is higher than the basic frequency, thus, analyze only the vertical vibration of floor slab. From the comparison between the different situations of Forced Vibration: it is concluded that the interference frequency range of $(14.7 \sim 14.9) \mathrm{Hz}$ of the screening machine is close to the first mode of the self-vibration is $14.1 \mathrm{~Hz}$ (Fig. 7), accordingly, so it has triggered flat curved coupling vibration. The dynamic response increases of concrete as the Stiffness of secondary beam and frame beam differ considerably and free vibration has greater amplitude. According to the information manufacturers provided, the frequency of screening machine is $900 \mathrm{r} / \mathrm{min}$ which consistent with the results obtained from the simulation analysis and the test results.

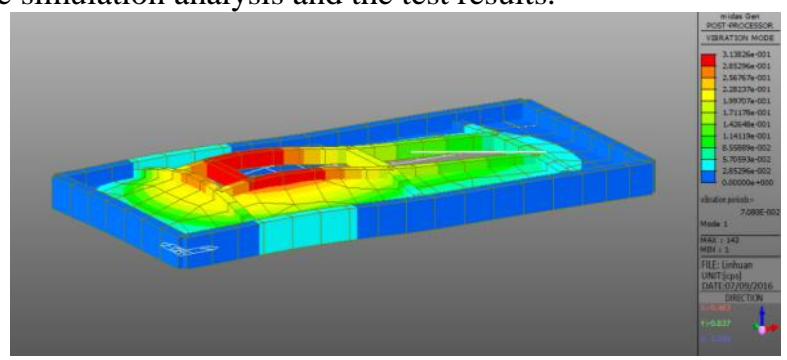

Figure 7. The first natural vibration modal of the structure

\section{CONCLUSION}

(1) Through the pre-judgment on vibration, this paper find out that the screening machine has great influence on the vibration of the structure and the vibration source which cause vibration is located at the fourth floor where are furnished with the broken unit and screening machine. The fundamental frequency of structure is $3.9 \mathrm{~Hz}$ and the vibration frequencies of $\mathrm{Z}$ direction were $14.9,14.7$ and 14.8 $\mathrm{Hz}$, these just shows that it has nothing to do with forced vibration on structure and the number of running equipments.

(2) The reason make the device below the beam plate produce resonance is bending force of screening machine, the interference frequency of the screening machine is close to the first mode of the self-vibration while dynamic response increases of concrete as the Stiffness of secondary beam and frame beam differ considerably.

(3) Through the detection result finds that the measure to replace vibration reduction system of equipment can not reduce intensity of vibration. Effective measures should be taken to enhance the stiffness of the secondary beams and floor slabs in order to ensure the safety of the plant structure.

\section{ACKNOWLEDGMENTS}

This work were supported by grant the second batch service project of State grid electric power company of Anhui province, 2016 (the biding number: AH16-FW-FZB003), the natural science research project of (research project No.KJ2015A046) and nature science research project of Anhui province (research project No. 1408085QE96). 


\section{REFERENCES}

[1] International Organization for Standardization. ISO 2631-2 Evaluation of human exposure to whole-body vibration-Part 2: Continuous and shock-induced vibration in buildings [S]

[2] Housner G W. Structural control: past, present, future [J]. Engrg Meeh ASCE, 1997, 123(9):897-971.

[3] Song T T. An overview of active and hybrid structural control research in the U. S. The strcu. Dyn [J]. Design of Tall Buildings, 1993, 2(1): 192-209.
[4] I Yoshida, H Kurose, S Fukui, et al. Parameter identification on active control of a structural model [J]. Smart Mater Struct, 1995, 4(1A): $82-90$

[5] Zhi Lunhai, Mao Wei. A multi-storey building vibration test and analysis of [J]. overseas building materials, 2005, 26 (6):44-46.

[6] Du Rui. Test and analysis of floor vibration of a multi-layer industrial building [J]. construction technology, 2010, 39 (3):66-69.

[7] Xue Gang, Wang Long, Wang Xijun. Test and analysis of vibration of vibrating screen in an industrial factory building [J]. construction technology, 2014 (S1):196-198. 